\title{
Refinement of Thalamocortical Arbors and Emergence of Barrel Domains in the Primary Somatosensory Cortex: A Study of Normal and Monoamine Oxidase A Knock-Out Mice
}

\author{
Alexandra Rebsam, ${ }^{1}$ Isabelle Seif, ${ }^{2}$ and Patricia Gaspar ${ }^{1}$ \\ 1/nstitut National de la Santé et de la Recherche Médicale U106, Hopital Pitié-Salpêtrière, 75013 Paris, France, and \\ 2Faculté de pharmacie, Université Paris Sud, 92296 Châtenay Malabry, France
}

In the rodent primary somatosensory cortex, the thalamocortical axons (TCAs) are organized into clusters that correspond to functional units in the periphery. Around these axons, neurons in layer IV aggregate as barrels. To understand how this organization emerges, we analyzed TCA development in mice that do not form barrels, the monoamine oxidase A knock-out (MAOA-KO), and in MAOA/5- $\mathrm{HT}_{1 \mathrm{~B}}$ receptor double-KO mice, which have a restored barrel field. We show that TCAs already attain cortical layer IV on the day of birth. They are uniformly distributed in this layer from postnatal day 0 (P0) to P2 and secondarily coalesce into barrel domains in layer IV, over a $3 \mathrm{~d}$ period (P3-P5), with no prepatterning in the deeper layers. In MAOA-KO mice, the uniform distribution of the TC projection is maintained, and no axon clusters emerge. Individual TCA arbors were traced after carbocyanine injections. At P1, TCAs were poorly branched and covered variable tangential widths, encompassing one to two prospective barrels. At P7 the number of TCA branches increased 10-fold in layer IV and became restricted to one barrel. In MAOA-KO mice, there was a 50\% reduction of the TCA terminal branches in layer IV, with a $40 \%$ increase in their tangential extent. These defects were corrected in the MAOA/5- $\mathrm{HT}_{1 \mathrm{~B}}$ double knock-out mice, indicating an effect of the presynaptic $5-\mathrm{HT}_{1 \mathrm{~B}}$ receptor on axon branching. Our results indicate that the barrel-deficient phenotype of MAOA-KO mice results from an altered refinement of the TCA arbors in their target layer IV, involving branch elaboration and collateral retraction during early postnatal life.

Key words: serotonin; activity-dependent mechanisms; synaptic stabilization; axon growth; axon branch formation; collateral retraction
The rodent barrel field is an appealing model to study the mechanisms underlying cortical map development. Each whisker of the snout is precisely mapped onto one barrel in layer IV of the primary somatosensory cortex (S1), and alterations of the whisker receptors during a sensitive developmental period cause corresponding modifications of the cortical representations (Woolsey and Van der Loos, 1970; Van der Loos and Woolsey, 1973). The thalamocortical (TC) projections, arising from the ventrobasal thalamic nucleus (VB), are thought to instruct the formation of the barrel field, because the thalamocortical axons (TCAs) are the first to display a pattern that resembles the distribution of the facial whiskers (Erzurumlu and Jhaveri, 1990; Schlaggar and O'Leary, 1994), whereas the cortical neurons in layer IV form prototypical barrels only 1-2 d later (Rice and Van der Loos, 1977; Jhaveri et al., 1991).

The mechanisms that underlie the formation of the barrel field are not yet understood. However, the use of genetically modified

Received Jan. 16, 2002; revised June 24, 2002; accepted July 18, 2002.

This work was supported by the Action Concertée Incitative of the French Ministry of Research and the Institut National de la Santé et de la Recherche Médicale. A.R. has a doctoral fellowship from the Ministry of Research. This work was partially initiated in the laboratory of Egbert Welker at L'Institut de Biologie Cellulaire et de Morphologie (University of Lausanne, Lausanne, Switzerland). We thank Constantino Sotelo for support and helpful comments and Chantal Alvarez and Aude Muzerelle for skilled technical help. We also thank Olivier Cases, Yorick Guitton, Christine Métin, Nicole Ropert, and Egbert Welker for useful discussions and critical reading of this manuscript.

Correspondence should be addressed to Patricia Gaspar, Institut National de la Santé et de la Recherche Médicale U106, Batitnent Pédiatrie, Hopital PitiéSalpêtrière, 47 boulevard de l'Hôpital, 75651 Paris cedex 13, France. E-mail: patricia. gaspar@u106.eu.org.

Copyright (C) 2002 Society for Neuroscience $\quad 0270-6474 / 02 / 228541-12 \$ 15.00 / 0$ mice has allowed to pinpoint a number of genes that appear to be necessary for the normal formation of barrels. Knock-out mice with selective alterations in neurotransmission (Cases et al., 1995; Welker et al., 1996; Iwasato et al., 1997, 2000; Hannan et al., 2001) or in growth-permissive molecules (Maier et al., 1999; Vanderhaeghen et al., 2000) have abnormal barrel fields. In some mutants, the primary event of barrel formation, the formation of periphery-related patterns by the TCAs, is altered, whereas in other mutants, only the secondary cytoarchitectonic organization of cortical neurons as barrels appears disrupted. We described previously the barrel field alterations of the monoamine oxidase A knock-out (MAOA-KO) mice and shown the essential role of an excess of 5-HT in these alterations (Cases et al., 1996; Vitalis et al., 1998). More recently, we determined, in MAOA/5-HT receptor double knock-out (DKO) mice, that the excessive activation of the $5-\mathrm{HT}_{1 \mathrm{~B}}$ receptor is responsible for the altered formation of barrels (Salichon et al., 2001). The consequence of this overactivation of $5-\mathrm{HT}_{1 \mathrm{~B}}$ receptors could be a reduced glutamate neurotransmission in the cortex that could alter activitydependent competition between TC synapses (Rhoades et al., 1994; Laurent et al., 2002). Alternatively, 5-HT could have a trophic effect on the growth of the TCAs (Lieske et al., 1999; Lotto et al., 1999). However, the relevance of these findings to the in vivo alterations has not been established. In adult MAOA-KO mice, a uniform pattern of TCA projections in layer IV was revealed by anterograde tracers (Cases et al., 1996), but it is not known when and how this abnormality occurs during development. Excess of 5-HT could act to prevent the initial segregation of TCAs in the cortex, or it could blur an initially precise pattern of projections by causing an exuberant growth. In the present 
Table 1. Number of cases processed for 5-HTT immunohistochemical analysis in the coronal or tangential plane, at the different postnatal ages, in wild-type $(\mathrm{C} 3 \mathrm{H})$, MAOA-KO, and MAOA/5-HT ${ }_{1 \mathrm{~B}}-\mathrm{DKO}$ mice

\begin{tabular}{|c|c|c|c|c|c|c|}
\hline & \multicolumn{3}{|c|}{ Coronal sections } & \multicolumn{3}{|c|}{ Tangential sections } \\
\hline & $\mathrm{C} 3 \mathrm{H}$ & MAOA-KO & DKO & $\mathrm{C} 3 \mathrm{H}$ & MAOA-KO & DKO \\
\hline $\mathrm{P} 0$ & 3 & 3 & 1 & 7 & 4 & 1 \\
\hline $\mathrm{P} 1$ & 3 & 3 & 1 & 6 & 4 & 2 \\
\hline $\mathrm{P} 2$ & 4 & 4 & 1 & 6 & 2 & 5 \\
\hline P3 & 6 & 4 & 5 & 5 & 4 & 4 \\
\hline P4 & 2 & 2 & 3 & 1 & & \\
\hline P5 & 4 & 3 & 5 & 2 & 1 & 1 \\
\hline P7 & 3 & 1 & 5 & & & \\
\hline
\end{tabular}

study, we took advantage of the transient expression of the serotonin transporter (5-HTT) in the VB (Lebrand et al., 1996, 1998) to conduct a detailed developmental study of the TC projection in normal and mutant mice. Our findings support the notion that excess 5-HT prevents the normal refinement of the TCAs from an initially diffuse projection. Morphological analyses of single axon arbors suggest that the emergence of axon clusters in layer IV of S1 involves both collateral branch addition and retraction. These two processes are altered by over-activating the $5-\mathrm{HT}_{1 \mathrm{~B}}$ receptors.

\section{MATERIALS AND METHODS}

Animals. Wild-type (WT) mice from the $\mathrm{C} 3 \mathrm{H} / \mathrm{HeOuJ}$ strain were purchased from a commercial source (Charles River, Saint-Aubin les Elbeuf, France). The MAOA-KO have been described by Cases et al. (1995) and the MAOA/5-HT $\mathrm{HB}_{1 \mathrm{~B}}-\mathrm{DKO}$ mice by Salichon et al. (2001). Homozygous breeding couples were raised and examined twice daily to determine the moment of birth with a $12 \mathrm{hr}$ precision. The morning of the plug was counted as embryonic day 0.5 (E0.5) and the day of birth as postnatal day $0(\mathrm{P} 0)$.

5-HTT Immunohistochemistry. The rationale for using 5-HTT as a TC marker has been described in previous reports that showed the transient expression of the 5-HTT gene in neurons of the sensory thalamic relays and the labeling of the TCA tracts with 5-HTT antibodies (Lebrand et al., 1996, 1998; Hansson et al., 1998).

One hundred twenty-one mice from P0 to P7 from the three genotypes were anesthetized with $4 \%$ chloral hydrate $(10 \mu \mathrm{l} / \mathrm{gm}$ weight $)$ and perfused through the aorta with $4 \%$ paraformaldehyde (PFA) in $0.12 \mathrm{M}$ phosphate buffer (PB). Sixty-six cases were used for sections in the coronal plane, and 55 cases from P0 to P6 (Table 1) were analyzed as tangential sections; the cerebral hemispheres were separated, and the cortex was flattened between two glass slides with spacers and postfixed overnight in the same fixative. After cryoprotection in PB with $30 \%$ sucrose for $\geq 1 \mathrm{~d}$, coronal sections of the brains or tangential sections of the flattened hemispheres were cut to $50-\mu \mathrm{m}$-thick sections on a freezing microtome and collected in PB. The serial tangential sections were numbered and maintained in strict topographic order during immunohistochemistry to evaluate patterning at different cortical depths. Sections were washed in PBS (PB with 9\% saline) and then in PBS+ (PBS with $0.2 \%$ gelatin and $0.25 \%$ Triton $\mathrm{X}-100)$. Sections were incubated overnight at room temperature with a rabbit polyclonal anti-5-HTT antibody (1:5000; Calbiochem, La Jolla, CA), washed in PBS+, and incubated $1.5 \mathrm{hr}$ with a biotinylated goat anti-rabbit antibody (1:200; Vector Laboratories, Burlingame, CA) and $1.5 \mathrm{hr}$ with a streptavidinbiotin-peroxidase complex (1:400; Amersham Biosciences, Les Ulis, France). Sections were then reacted in a solution containing $0.02 \%$ diaminobenzidine, $0.003 \% \mathrm{H}_{2} \mathrm{O}_{2}$, and $0.6 \%$ nickel ammonium sulfate in $0.05 \mathrm{~m}$ Tris buffer, $\mathrm{pH}$ 7.6. Sections were mounted on gelatin-coated slides, counterstained with $0.1 \%$ methyl green, and coverslipped in Eukitt.

Fluoxetine treatment. Three normal P1 pups were injected subcutaneously with fluoxetine $(10 \mathrm{mg} / \mathrm{kg}$; dissolved in saline) $3.5 \mathrm{hr}$ before being perfused with PFA and processed as described above. The brain sections were processed for 5-HT immunohistochemistry, using the monoclonal rat anti-5-HT antibody (1:50; Chemicon, Temecula, CA) and a rabbit biotinylated anti-rat antibody (1:200; Dako, High Wycombe, UK). The protocol for 5-HT immunohistochemisty is as described above.

Double immunostaining of 5-HTT and bromodeoxyuridine. Pregnant dams were injected intraperitoneally with a single dose of bromodeoxyuridine (BrdU) $(25 \mathrm{mg} / \mathrm{kg}$ in saline) at E14.5 (four $\mathrm{C} 3 \mathrm{H}$ pregnant dams, with litters of four to seven pups each). Pups from the same litters were killed sequentially at P0, P1, and P7. Pups were killed and perfused as described previously. Brains were postfixed overnight, cryoprotected, and cut on a cryostat to $20-\mu \mathrm{m}$-thick sections.

Sections were rinsed twice in PBS and then in PBST (PBS with $0.2 \%$ gelatin and $0.075 \%$ Triton X-100) and were incubated overnight with a rabbit polyclonal anti-5-HTT antibody (1:2000; Calbiochem). Sections were washed in PBST and incubated for $1 \mathrm{hr}$ with a CY3-linked goat anti-rabbit antibody (1:200; Jackson ImmunoResearch, West Grove, PA). Sections were washed, incubated for $45 \mathrm{~min}$ in $2 \mathrm{~N} \mathrm{HCl}$ (in PBST), washed again, and incubated overnight with a mouse monoclonal anti-BrdU antibody (1:300; Progen Biotechnik, Heildelberg, Germany). After washing, sections were incubated for $1 \mathrm{hr}$ with a fluorescein isothiocyanate-linked sheep anti-mouse antibody (1:50; Amersham Biosciences). The sections were washed in PBST (four times for $10 \mathrm{~min}$ each) and then coverslipped in Mowiol 4-88 (Calbiochem). All reactions were made at room temperature.

Carbocyanine tracing. Carbocyanine 1-1'-dioactadecyl-3,3,3',3'-tetramethylindocarbocyanine perchlorate (DiI))Molecular Probes, Eugene, OR) injections were done at P1 $(n=74)$, P2 $(n=14)$, and P7 $(n=53)$ on mice from the three genotypes.

For bulk injections of the VB at P1 and P2, mice were perfused with PFA ( $4 \%$ in PB), and the brains were kept in the same fixative. Small crystals of carbocyanine were placed into the VB after making a section at the mesencephalo-diencephalic junction, rostrally to the superior colliculus. The dye was allowed to migrate for $1-3$ weeks at $37^{\circ} \mathrm{C}$ in PFA, and the hemispheres were cut into $100 \mu \mathrm{m}$ sections in the coronal plane, using a vibratome.

Small injections of tracers at P1 and P7 were done on the thalamocortical slice preparation (Agmon et al., 1993). Briefly, pups were killed by cooling on ice and decapitated, and the whole head was immersed in ice-cold PBS. The brains were extracted, maintained in cold PBS, and cut to $400-\mu \mathrm{m}$-thick slices in a plane oriented at $55^{\circ}$ to the sagittal plane, which maintains the integrity of the thalamocortical connection (Agmon and Connors, 1991). The same angle of section was used at P1 and P7. Using a picospritzer and fine-tipped glass pipettes $(20-60 \mu \mathrm{m}$ in diameter), small injections of carbocyanine $(0.4 \%$ in $4 \%$ dimethylformamide and $10 \%$ sucrose) were placed into the $\mathrm{VB}$, from the caudal face of the section, under the control of a binocular dissecting microscope. The slices were thereafter placed into PFA, in individual culture wells, maintained at $37^{\circ} \mathrm{C}$, and examined 1 week later, rostral side up, using a confocal microscope (TCS; Leica, Nussloch, Germany). Serial optical sections through the $400-\mu \mathrm{m}$-thick slice were made and collapsed into a two-dimensional image (extended focus or three-dimensional rotation function). The position of layer $\mathrm{V}$, relative to the axon arbors, was determined after counterstaining the sections with bisbenzimide $(0.01 \%$ in PBS for $1 \mathrm{hr}$ ).

Analysis. The TCAs were redrawn from the composite confocal image. These images were transformed into a negative image with Adobe PhotoShop (version 6.0; Adobe Systems, San Jose, CA) and printed out at a final magnification of $304 \times$. Transparent foil was superimposed on the prints to redraw the axons. This procedure is shown for one fiber in Figure 7. The axons were selected for analysis when they fulfilled the following criteria: (1) they were localized in the posteromedial barrel subfield (PMBSF), corresponding to the large whiskers, (2) they could be followed from the white matter to layer IV, (3) the traced axon arbor could be clearly distinguished from neighboring labeled axons in the stack of confocal slices, and (4) the TC arbor appeared to be entirely included within the thickness of the section.

The redrawn axons were reduced and digitized to be analyzed with the MetaMorph software program (Universal Imaging, West Chester, PA). To determine the maximal tangential extent of the TCAs in the plane of the thalamocortical section, we projected the most distal limits of the TC arbors onto a line parallel to the cortical surface and measured the distance between these two points. To evaluate a branching index of the TCAs, we counted all of the terminal endpoints of an individual TCA after its entry into the cortex. The completeness of these TC arbors was easy to assess at P1, because many axon branches were tipped with growth cones. At P7, we cannot exclude that some branches extend beyond the $400 \mu \mathrm{m}$ section analyzed; this could lead to an underestimate 


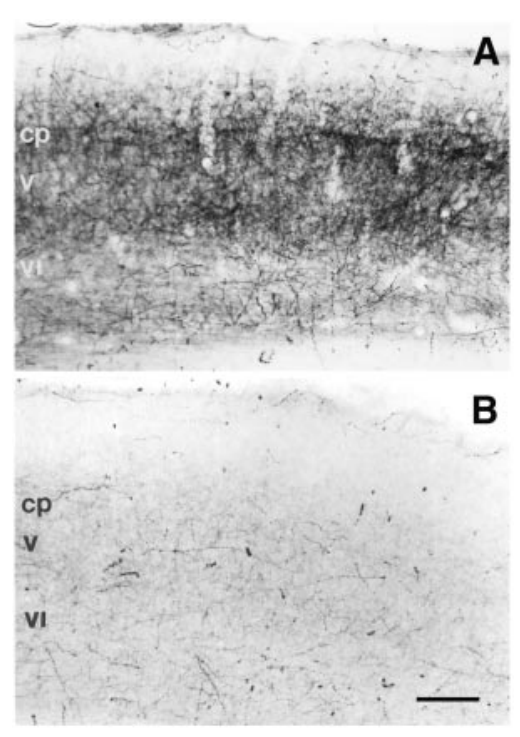

Figure 1. 5-HT immunostaining preferentially labels thalamocortical axons at P1. During development, 5-HT is present in fibers arising from the raphe as well as in TCAs, which express the 5-HT transporter (Lebrand et al., 1996). A, At P1, the 5-HT labeling is distributed as two dense bands, one in the cortical plate $(c p)$ and another at the border between layers $\mathrm{V}$ and VI, with a pattern similar to that of anterogradely labeled TCAs shown in Figure $4 D$. $B$, To abolish 5-HT staining in the TCAs, we treated acutely mice with fluoxetine, an inhibitor of 5-HT uptake. Raphe fibers, which synthesize 5-HT, are not affected by this treatment. They are much less abundant than the TCAs and are sparsely distributed in the cortical plate $(c p)$ and layers V to VI and I. Scale bar, $100 \mu \mathrm{m}$.

of the total number of terminal branches in the rostrocaudal dimension. Thus, our estimate provides essentially a comparative view of the axon arbors in a comparable mediolateral plane for the different ages and the different genotypes. Statistical analyses were performed using the ANOVA test, Student's $t$ test, and the comparison of variance ( $F$ test).

\section{RESULTS}

\section{5-HTT immunohistochemistry as a marker of the developing TCAs}

Previous reports have shown that the 5-HTT gene is transiently expressed in neurons of the ventrobasal thalamic relay nuclei, whereas other thalamic neurons that project to S1 (the intralaminar thalamic nuclei, zona incerta, and nucleus posterior thalami) do not express this gene (Lebrand et al., 1996, 1998; Hansson et al., 1998). The transporter is targeted to the entire axonal compartment allowing a clear visualization of the TCAs within the cortex (Lebrand et al., 1998); generally, the axon terminals are more clearly labeled than the axon tracts. Because 5-HTT is also present in the raphe serotoninergic axons, to determine the relative contribution of the raphe and the thalamic axons, we performed 5-HT labeling before and after inhibition of 5-HT uptake by administering fluoxetine (Fig. 1) (Lebrand et al., 1996; Cases et al., 1998). In untreated P1 pups, the 5-HT and 5-HTT labeling completely overlapped (compare Figs. $1 A, 4 B$ ), whereas after fluoxetine treatment, the 5-HT disappeared from the TCAs (Fig. $1 B$ ). This residual raphe innervation consists in scattered fibers in layers V to VI and upper layer I, which contrasts with the dense continuous bands of labeling of layers VIa and IV of the untreated cases (Fig. 1).

5-HTT immunostaining can be compared with bulk anterograde tracing of the TCAs after carbocyanine injections into the thalamus at P2, which showed comparable laminar distributions (see Fig. 4D).

\section{Emergence of tangential domains in $\mathrm{S} 1$ in wild-type mice}

5-HTT labeling was followed on serial tangential sections (Figs. 2, 3 ) and coronal sections (Fig. 4), allowing to evaluate complementary aspects of the TCA topography.

During the first $2 \mathrm{~d}$ of life $(\mathrm{P} 0-\mathrm{P} 1)$, the TC fibers appeared to be diffusely distributed within $\mathrm{S} 1$, and separations were visible only between the three principal domains of S1 that correspond to sensory afferents from different parts of the body: (1) the sensory afferents from the hindpaw and forepaw (lemniscal afferents), (2) the afferents from the lower lip, (3) the afferents from the large snout vibrissae, which form the posteromedial barrel subfield, and (4) the small whiskers of the anterior snout (AS) (Woolsey and Van der Loos, 1970; Welker, 1971). At this stage, no additional clustering of the TCAs was noted within each of these cortical S1 domains. In particular, no 5-HTT-immunoreactive (IR) rows were visible within the PMBSF in our serial sections in the tangential or coronal planes (Fig. $2 A, 4 A, B$ ).

At $\mathrm{P} 2$, separations emerged within the principal domains of S1: between the hindpaw and forepaw representations and within the PMBSF in which 5-HTT-IR rows could be seen (Fig. 2B). At P3, additional separations became visible within the different S1 domains. The separations between the representation of the different body parts became clearer (e.g., between the AS and lower lip and between the PMBSF and hindpaw representations) (Fig. 2C). Moreover, an outline of the individual axon clusters began to be detectable within the central rows of the PMBSF in both the tangential (Figs. $2 C, 3 A$ ) and coronal planes (Fig. 4E). However, no axon clusters were yet observed in the rostral parts of the barrel field (the AS). From P3 to P5, the axon clusters in the PMBSF became more clearly separate because of a reduction in the amount of TC fibers between the barrel domains (Figs. 3, $4 E, F)$. Furthermore, the axon clusters became visible in the AS and forepaw representations (Fig. 3B).

Thus, the segregation of TCAs into well delimited tangential domains appears to emerge from an initially diffuse pattern at birth and proceeds gradually. A first separation becomes visible between the afferents that correspond to different body parts (trigeminal and lemniscal sensory afferents), followed by a separation of these territories into subdomains. In the PMBSF, a separation of TCAs into whisker rows occurs by P2 and is followed by a separation of these rows into axon clusters by P3 to P4. A similar sequence of emerging patterns was described in rats but with a $2 \mathrm{~d}$ advance because a row-like patterning of the TCAs is already visible at birth (Rhoades et al., 1990; Schlaggar et al., 1994; Auso et al., 2001).

Our preparations showed no evidence for a prepatterning of TCAs in the deep cortical layer. In serial tangential sections through the flattened cortex, when axon clustering became visible, it was generally most clearly observed in the superficial sections (from 100 to $200 \mu \mathrm{m}$ below the pial surface at P2 and P3) and less sharp in the deeper sections (Fig. 3A). Similarly, at P5, emerging axon clusters in the AS were more clearly defined in the upper cortical layers, although patterning could be followed into the deeper layers (Fig. 3B). In the coronal sections, TCAs formed bundled radial fascicles running radially within layer $\mathrm{V}$; however, axon clusters were more frequently observed in layer IV than in layer VI at all the ages examined (P3-P7). We saw no cases in which periphery-related patterns of TCAs were present in layer VI without being also present in layer IV. 
Figure 2. Progressive individualization of tangential domains in $\mathrm{S} 1$. In the three genotypes, WT $(A-C)$, MAOA-KO $(D-F)$, and MAOA $/ 5-\mathrm{HT}_{1 \mathrm{~B}}-\mathrm{DKO}(G-I)$ mouse pups from the same litters were analyzed at P1, P2, and P3. 5-HTT immunostaining was performed on serial tangential sections of flattened hemispheres. All pictures are similarly oriented; rostral is to the left, and dorsal is up. 5-HTT labels all of the TC projection of the sensory cortices, including the somatosensory $(S 1, S 2)$, visual $(V 1)$, and auditory $(A 1)$ cortices. The main divisions in $\mathrm{S} 1$ are shown in $C$ : the mystacial vibrissa subfield $(\mathrm{mb})$, anterior snout (as), lower lip ( $(l)$, hindpaw $(h p)$, and forepaw $(f p) . A-C$, In the $\mathrm{C} 3 \mathrm{H}$ WT mice, the emergence of tangential domains is sequential; in the mystacial vibrissae field, a diff use pattern of staining is observed at P1, barrel rows emerge at $\mathrm{P} 2$, and individual barrels emerge at P3 (arrowheads show the limits between the barrel rows). Note that the barrels are first delineated in the central rows. Similarly, there are no separations between the hindpaw and forepaw representations at $\mathrm{P} 1$, and these separations become clear at $\mathrm{P} 3$ as indicated by the arrow; furthermore, separations between the anterior snout and lower lip representations become sharper over time. $D-F$, In MAOA-KO mice, the separations between the different S1 domains are not as clear as in control mice, and no row-like, or barrel-like, pattern emerges in the mystacial vibrissae field. $G-I$, In $\mathrm{MAOA}_{5}-\mathrm{HT}_{1 \mathrm{~B}}-\mathrm{DKO}$ mice, a normal timing of the separation of the S1 domains and cortical barrels are restored. Scale bar, $500 \mu \mathrm{m}$.
MAOA-KO
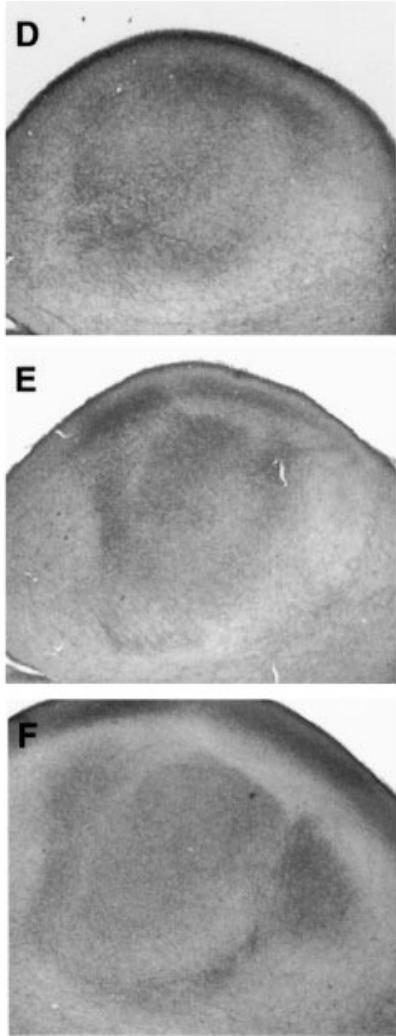

MAOA/5HT1B-DKO
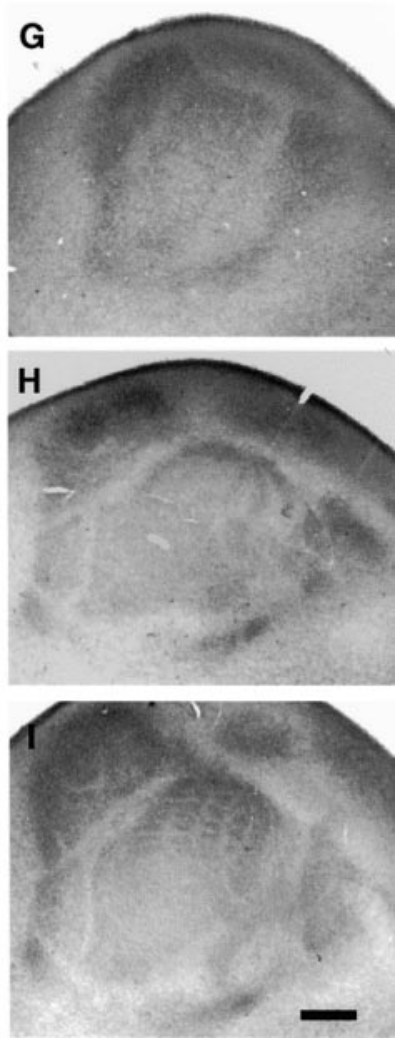

P3
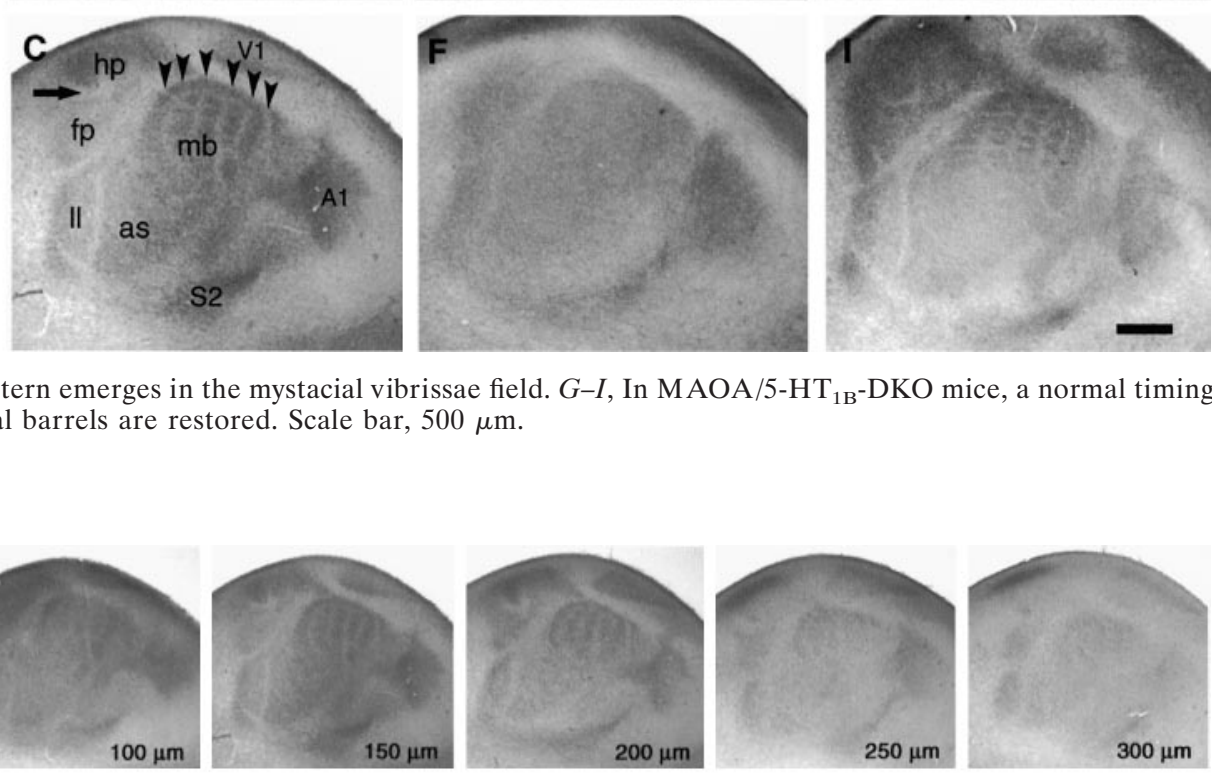

Figure 3. Emergence of periphery-related patterns is observed most clearly in the upper layers of the cerebral cortex, as viewed from serial tangential sections through S1. The hemispheres were flattened between two glass slides and sectioned in the tangential plane to $50-\mu \mathrm{m}$-thick sections. The serial order was maintained throughout the 5-HTT immunohistochemical procedure. The distance from the pial surface was estimated by counting the number of sections from the first section through the pia matter. Two sets are shown at P3 and P5. TCA patterning is most clearly visible at $150 \mu \mathrm{m}$ below the pial surface at P3 and at $200 \mu \mathrm{m}$ below the pial surface at P5, which corresponds to the position of layer IV at that age. Scale bar, $500 \mu \mathrm{m}$.
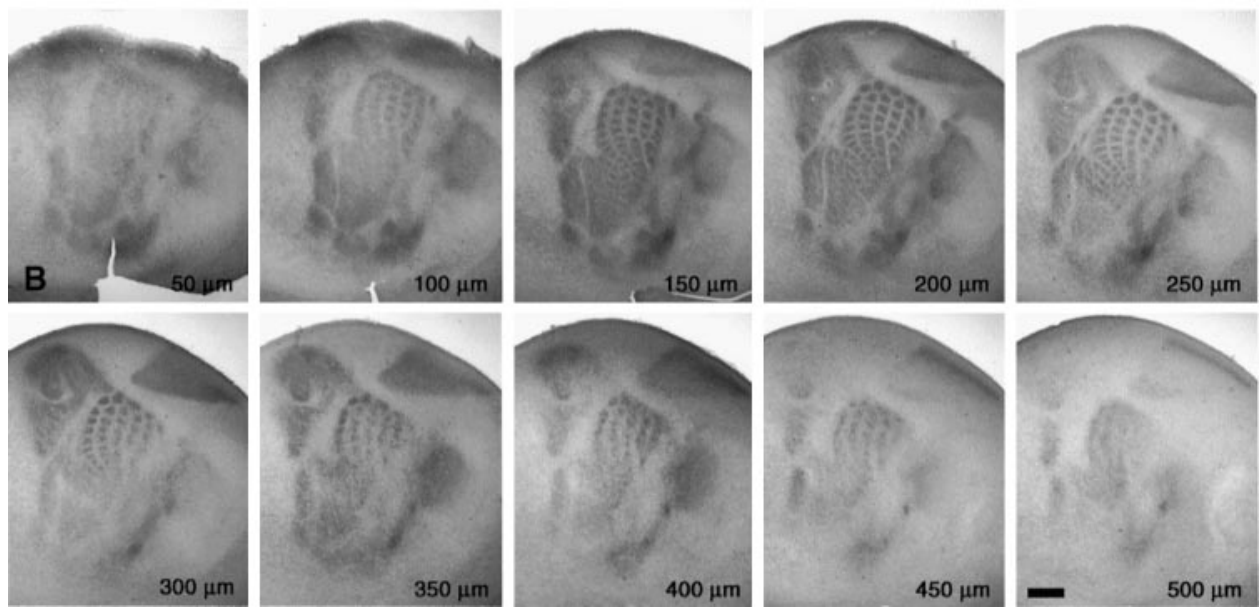

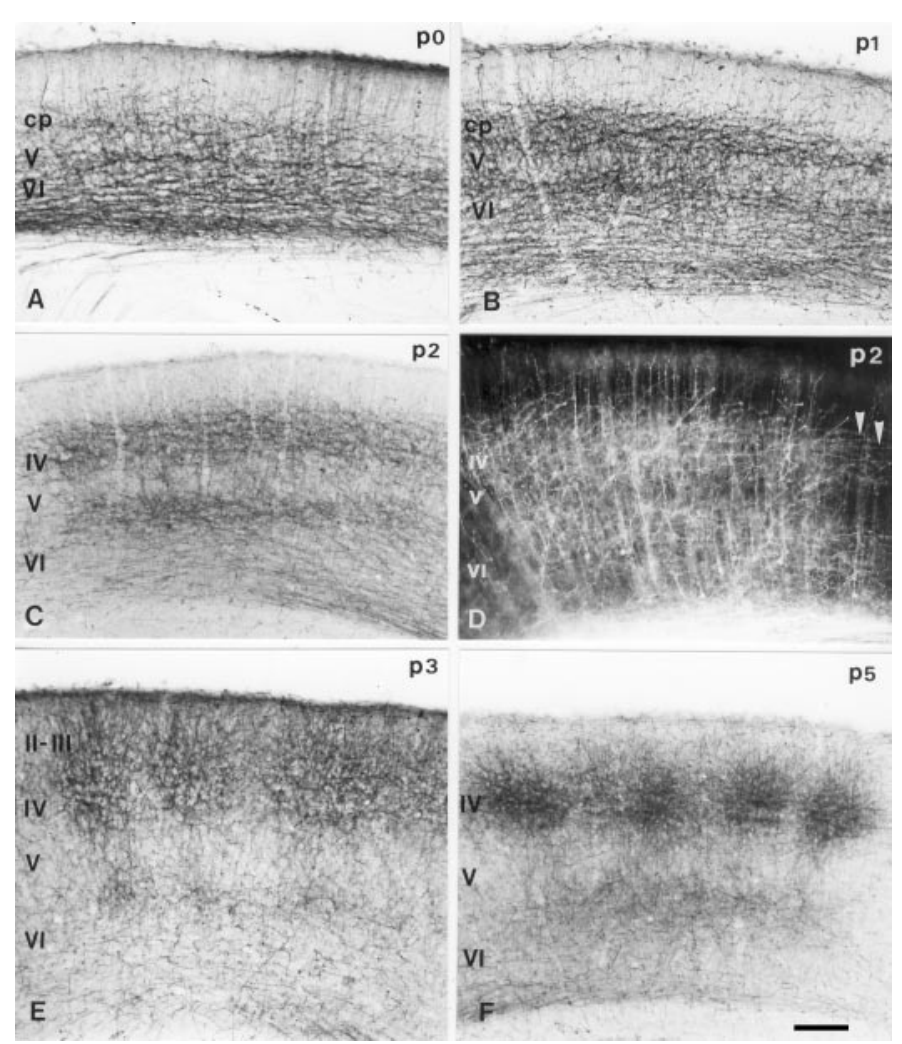

Figure 4. Progressive laminar and tangential refinement of the TCAs in the somatosensory cortex. $A-C, E, F$, The distribution of the TCAs labeled with 5-HTT is shown on coronal sections at comparable levels of the posteromedial barrel subfield, from the day of birth (P0) until P5. A, At P0 ( $>12$ hr after birth), a dense and broad fiber network is visible in the deep cortical layer, essentially in layer VI, and a lighter tangential network is visible in the cortical plate. $B$, At P1, the 5-HTT-positive band in layer VI becomes restricted to the top part of layer VI at the junction with layer $\mathrm{V}$; the band in the cortical plate enlarges. $C$, At P2, the labeling in layer VI becomes narrower. $E$, At P3, TCAs begin to separate into barrels in both layers IV and VI, and a transient extension of the TCAs extending up to the pial surface is noted. F, At P5, the TCAs have retracted from layer II and form well delimited axon clusters in layer IV. $D$, The distribution of TCAs labeled after bulk injection of carbocyanine is shown at P2. The distribution of the fibers resembles that observed with 5-HTT at the same age $(C)$, with horizontally oriented fibers in layer IV (arrowheads). This technique, however, also back labels corticothalamic neurons, explaining that fiber network observed in layer VI is more dense than with 5-HTT. Scale bar, $100 \mu \mathrm{m}$.

\section{5-HTT-labeled TCAs reach layer IV neurons on the day of birth}

The date of arrival of TCAs in their target layer has been estimated variously with anterograde tracing studies [P0 by Senft and Woolsey (1991) and P2 by Agmon et al. (1993)], possibly because of difficulties in identifying the afferents and target cells on the same section. With 5-HTT immunohistochemistry, a thick band of TCAs was observed in the deep tier of the cortex extending throughout layer VI, and a second, thinner band of fibers was noted in the cortical plate (CP) (Fig. 4A). The extent of the upper cortical band depended on the timing of the experiment; in "early" P0 cases, perfused $<12 \mathrm{hr}$ after birth, the 5-HTT fibers just reached the CP but did not form a clear separate stratum of fibers (Fig. $5 A$ ), whereas in $\mathrm{P} 0$ cases, which were examined $>12 \mathrm{hr}$ after birth, TCAs formed a relatively thick band in the cortical plate (Figs. $4 A, 6 A$ ).

From P1 to P2, the two continuous bands of 5-HTT-IR fibers were found in all of the cases, one in the cortical plate and the other in the upper part of layer VI (Figs. $4 B, C, 5 D$ ). Over the first postnatal days, the amount of 5-HTT-labeled fibers tended to decrease in layer VI and to condense in the upper part of layer VI, layer VIa, at the junction between layers V and VI. In contrast, the amount of stained fibers in the upper band in the cortical plate increased; the 5-HTT-positive fibers formed a dense meshwork (Fig. 4C) comprising many tangentially oriented fibers. A similar distribution of the TCAs was observed after bulk injections of carbocyanine in the VB (Fig. 4D).

To determine the exact localization of the TCAs in the cortical plate, during the first postnatal days, we birth dated the layer IV neurons by injecting BrdU at E14.5 (Fairen et al., 1986). Pups from the same litter were killed at $\mathrm{P} 0, \mathrm{P} 1$, and $\mathrm{P} 7$ to ensure that we had indeed labeled the layer IV neurons (Fig. 5G-I). Double immunohistochemical labeling of 5-HTT and BrdU showed that the 5-HTT-labeled fibers reached layer IV neurons at P0 (Fig. $5 A-C$ ), and, at P1, the dense horizontal network of 5-HTT-IR fibers was localized among the layer IV neurons of the cortical plate (Fig. $5 D-F)$.

Thus, the TC fibers already reach layer IV at $\mathrm{P} 0$ and form a continuous uniform band in this layer before clustering into separate periphery-related domains. In layer VI, TC fibers are initially broadly distributed and progressively become restricted to the upper part of layer VI, before clustering into tangential domains that are in register with the axon clusters of layer IV, but are less clearly defined.

\section{Lack of tangential patterning but normal laminar development of TCAs in MAOA-KO mice}

MAOA-KO mice do not develop barrels (Cases et al., 1996). To determine when this abnormality occurs during development, we followed the development of TCA patterning in the mutant mice.

The outline of the TCAs in MAOA-KO mice was similar to that of control mice until P1, and the laminar development of the 5-HTT fibers followed an identical time course (Fig. 6). TC ingrowth was also examined during embryonic life, at E15, when the TC fibers reach the cortex, and at E18, when they start invading it; no difference was observed between the control and MAOA-KO mice (data not shown). At P0, the 5-HTT fibers reached the lower part of the cortical plate in MAOA-KO mice as in control mice, indicating a normal and timely ingrowth of the TC fibers (Fig. 6D). During the subsequent postnatal days, a laminar sharpening of the TC projection was noted in MAOA-KO mice (Fig. 6E) as in the control mice (Fig. 6B). There was a decrease in the amount of 5-HTT-IR fibers in the lower part of layer VI between P0 and P3 (Fig. 6D,E) and a parallel decrease of stained fibers in layers II to III between P3 and $\mathrm{P} 7$ (Fig. 6E,F).

In contrast, there were differences in the tangential distribution of the TC fibers. At P1, the limits between the different sensory areas (V1, A1, S1, and S2) were less marked than in the wild-type mice (Fig. 2, compare $A, D$ ). Similarly, at P2, the separation between the different body parts of S1 was less clearly drawn than in controls; for instance, the limits between the hindpaw and forepaw representations could not be distinguished, nor could the separation between the anterior snout and lower lip (Fig. 2, compare $B, E)$. Furthermore, no row-like organization of the TCAs emerged in the PMBSF. At P3, and thereafter, the pattern remained diffuse (Fig. $2 F$ ). Thus, although the initial development of the TC projection and its laminar refinement proceeds normally in MAOA-KO mice, the secondary tangential delimita- 


\section{HTT}
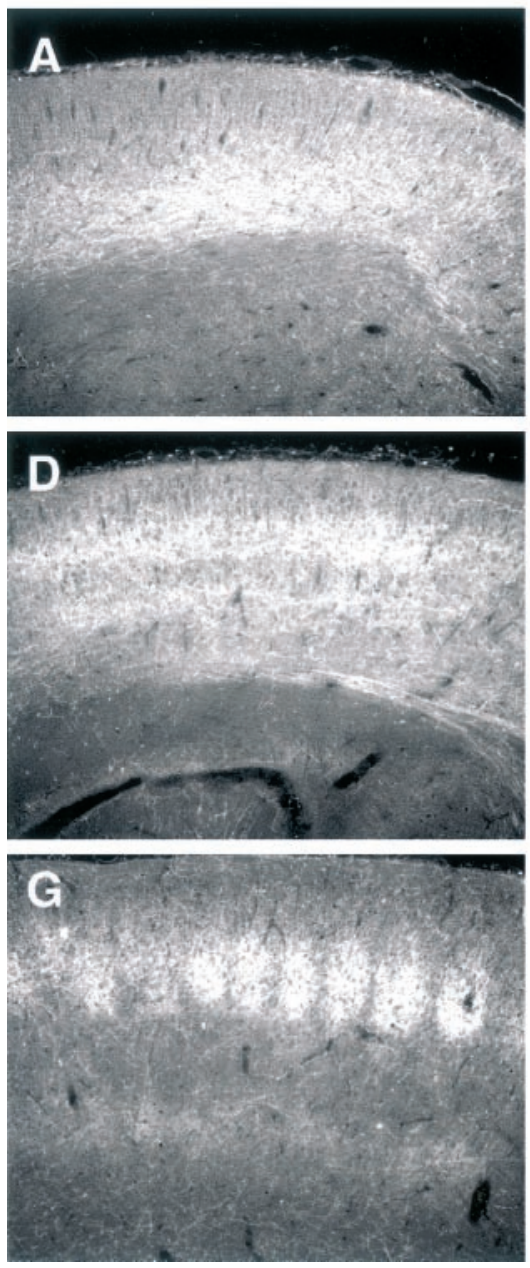

BrdU
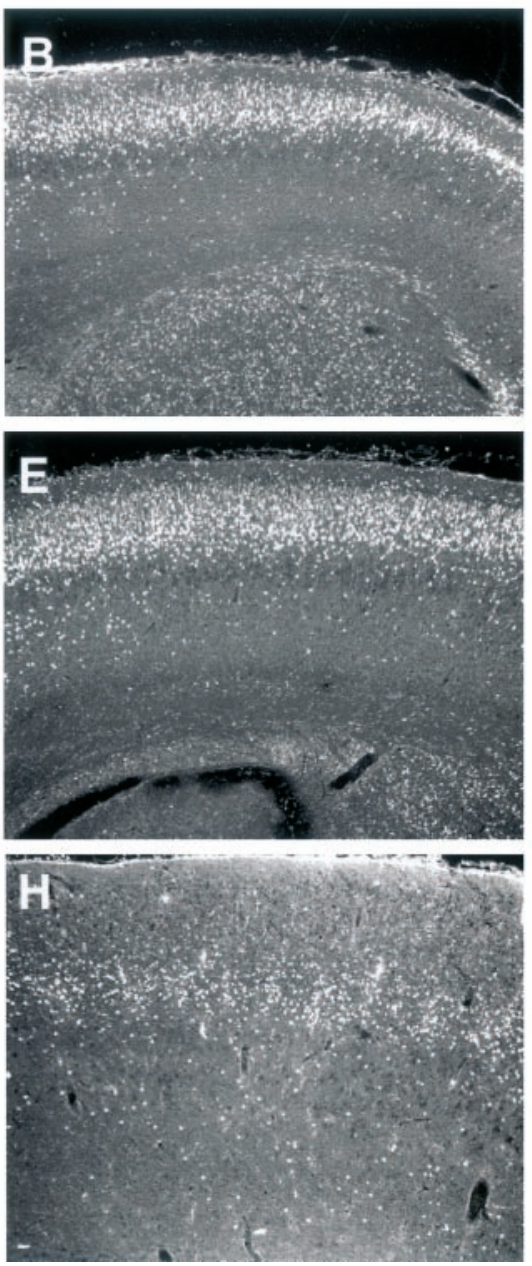
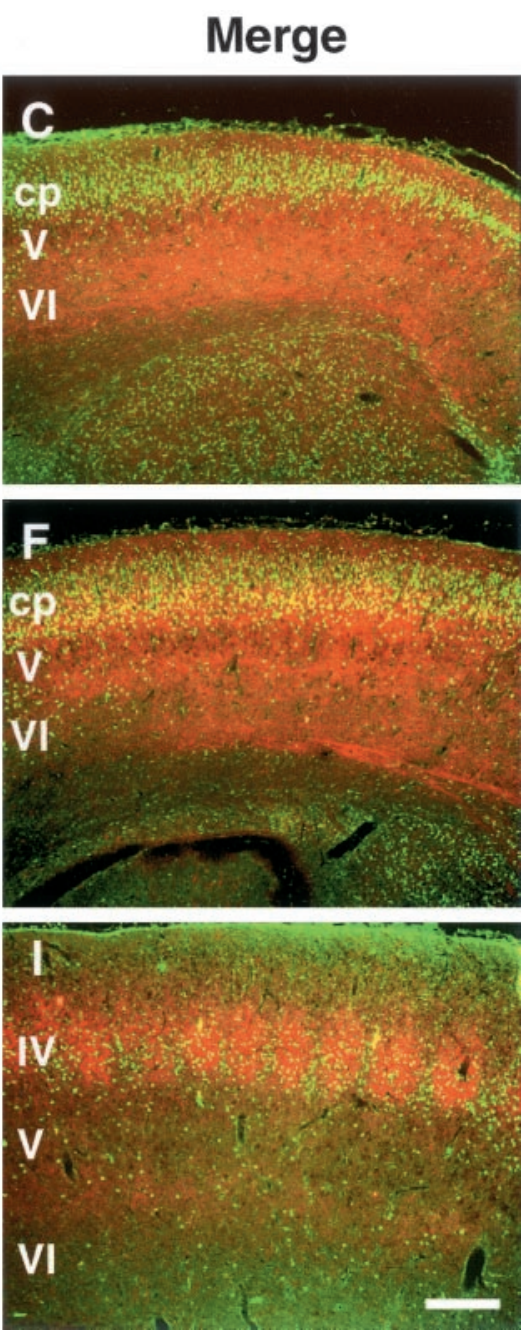

Figure 5. TCAs reach their target layer IV neurons on the day of birth. Layer IV neurons were birth dated with BrdU injections at E14.5, and animals from the same litter were killed at P0, P1, and P7. Sections were double immunostained for 5-HTT to visualize the TCAs $(A, D, G)$ and with BrdU to visualize the layer IV neurons $(B, E, H) . A-C$, At $\mathrm{P} 0(<12 \mathrm{hr}$ after birth), the 5-HTT-labeled TCAs (red) have already reached the BrdU-labeled layer IV neurons ( green) in the cortical plate. $D-F$, At P1, the TCAs form a continuous band of fibers in the lower cortical plate $(c p)$, among the BrdU-labeled layer IV neurons. A second band of label is visible at the junction of layers V and VI, the future layer VIa. $G-I$, At P7, the precise localization of BrdU-labeled neurons in layer IV shows that the timing of this injection was correct; 5-HTT-labeled clusters of fibers are surrounded by layer IV neurons. Scale bar, $200 \mu \mathrm{m}$.

tion of TCAs into regional domains within S1 and into individual barrel domains is deficient.

The altered distribution of the TCAs contrasts with a normal development of the thalamic barreloids, corresponding to the large mystacial vibrissae at P3 (cytochrome oxidase and metabotropic glutamate receptor 5 immunohistochemistry; data not shown) [for similar data at P6, see Cases et al. (1996) and Salichon et al. (2001)]. Thus, the excess of 5-HT selectively affects the patterning of the thalamic axon terminals but does not disorganize the patterning of afferents from lower sensory relays. This also indicates that different and independent mechanisms operate to aggregate the thalamic neuronal perikarya and segregate their terminal axons at the time when periphery-related patterns emerge.

\section{Timely patterning of TCAs in the MAOA/5-HT 1B $^{-D K O ~ m i c e . ~}$}

The MAOA/5-HT ${ }_{1 \mathrm{~B}}$ double knock-out mice have been characterized previously. It has been shown that a normal patterning of the barrel field is almost completely restored in these mice at P7, despite the lasting increase of 5-HT levels (Salichon et al., 2001). 5 -HTT immunostaining in the MAOA/5-HT $1 \mathrm{~B}$-DKO showed a normal timing of the TC fiber patterning in both the tangential (Fig. 2G-I) and coronal (Fig. 6G-I) planes. The laminar distribution of the TCAs was comparable with that of WT mice. TCAs began forming axon clusters by P3 (Fig. 6H), which were clearly delimited in layer IV at P7, although there was no clear formation of axon clusters in layer VI (Fig. 6I).

Thus, the developmental sequence of emergence of peripheryrelated axonal patterns appears to be normalized in layer IV in the $\mathrm{MAOA} / 5-\mathrm{HT}_{1 \mathrm{~B}}-\mathrm{DKO}$ mice.

\section{Development of TCA arbors in normal and barrel-deficient mice}

To understand whether the segregation defects of TCAs in the MAOA-KO result from changes in the individual terminal arbors, we did small carbocyanine (DiI) injections in the VB at P1 and P7 (Fig. 7). Although this method often labels more than one 

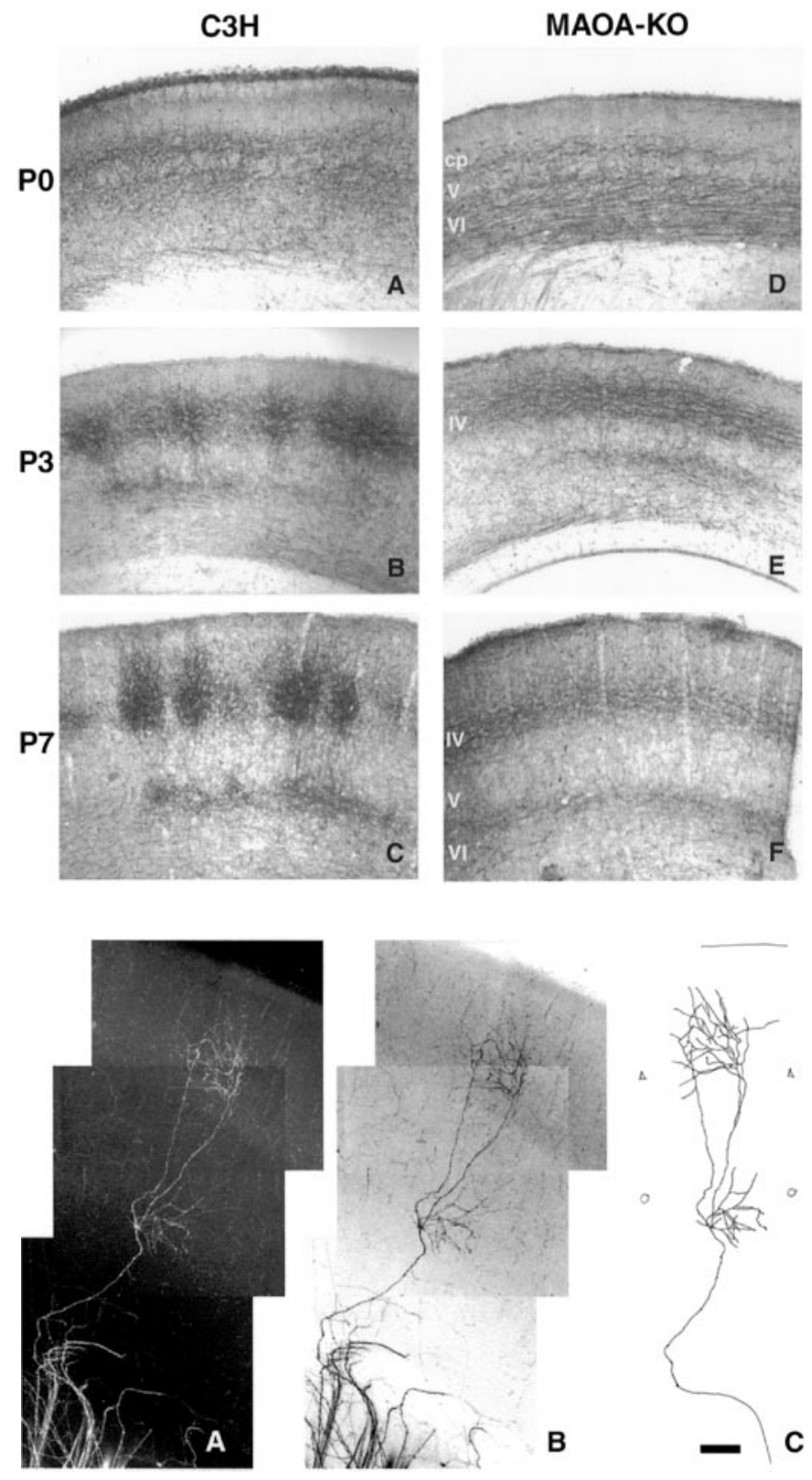

Figure 7. Procedure used to reconstruct single axon arbors after carbocyanine injections in the thalamocortical slice preparation. $A$, Cases with small injection and isolated labeled fibers are selected. In this P7 case, corresponding to a MAOA/5- $\mathrm{HT}_{1 \mathrm{~B}}-\mathrm{DKO}$ mouse, four axons are visible in layer VI, but only one axon arborizes within the thalamocortical slice. Serial confocal sections of this $400-\mu$ m-thick slice were done and then compacted into a single image using the extended focus program. $B$, The negative image was produced with Adobe PhotoShop version 6.0 (Adobe Systems) and printed out. $C$, Axon arbors were then manually redrawn from these prints for quantitative analysis. Scale bar, $100 \mu \mathrm{m}$.

TCA in the same area, the use of confocal analysis allowed to follow with certainty single fibers from their entry point in layers V I to IV without missing branches or conf using them with nearby labeled fibers (Fig. 7).

It is known that the size of TCA clusters varies across the barrel field; barrels in the PMBSF are larger than rostral barrels in the AS (Jensen and Killackey, 1987) and mature first (present observations; Rhoades et al., 1990). Thus, care was taken to sample TCAs only from the PMBSF. All of the reconstructed

\section{MAOA/5HT1B-DKO}
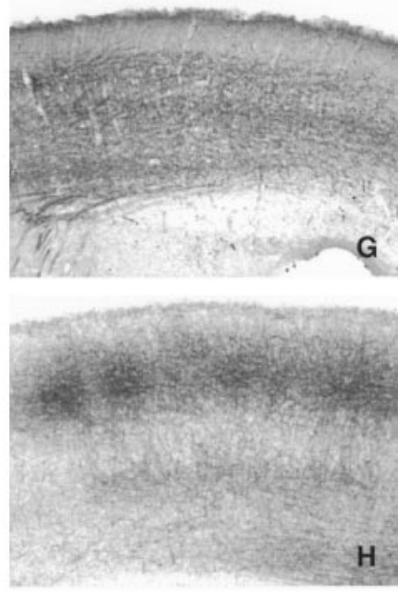
TCAs in MAOA-KO and MAOA/5$\mathrm{HT}_{1 \mathrm{~B}}$-DKO mice. The development of 5-HTT patterning was compared in $\mathrm{C} 3 \mathrm{H}$ wild-type mice $(A-C)$, MAOA-KO mice $(D-F)$, and MAOA $/ 5-\mathrm{HT}_{1 \mathrm{~B}}-\mathrm{DKO}$ mice $(G-I)$. At $\mathrm{P} 0(A, D, G)$, the laminar distribution of TCAs is similar in all three genotypes, indicating that the initial development is normal in MAOA-KO mice. At $\mathrm{P} 3(B, E, H)$, barrels emerge in layer IV in $\mathrm{C} 3 \mathrm{H}$ and $\mathrm{MAOA} / 5-\mathrm{HT}_{1 \mathrm{~B}}-\mathrm{DKO}$ mice but not in MAOA-KO mice; however, the confinement of the TCAs to the layer V to $\mathrm{VI}$ frontier proceeds as in WT mice. At P7 $(C, F, I)$, barrels are well developed in layer IV of the WT and MAOA-5- $\mathrm{HT}_{1 \mathrm{~B}^{-}}$ DKO mice. In the MAOA-KO, no tangential delimitation of barrels is visible, but TCAs in the top cortical layers retract. Note that the delimitation of axon clusters is more clearly set out in layer IV than in layer VI. Scale bar, $100 \mu \mathrm{m}$.

axons at P7 and most axons at P1 (75\%) were in the central part of the PMBSF as estimated from the position in the dorsoventral plane, although the precise position (among the whisker row, for instance) was not determined. No correlation was noted between the mediolateral position and tangential dimensions or branching index of TCAs; however, we cannot exclude that some of the variability observed is related to the position of TCAs.

\section{Normal development of TCAs}

At P1, a total of 42 individual axon arbors was followed from layer VI up to their terminal endpoints generally tipped with growth cones. The TCAs had a highly variable course that is depicted in Figure 8; some fibers (12 of 42) maintained a radial direction from layers VI to II (Fig. 8A,B), other axons (10 of 42) ran tangentially in layer IV with no arborization (Fig. $8 C, D$ ), and a third group of TCAs (7 of 42) had more complex arborization in layer IV (Fig. 8E-H). Axon collaterals (discounting axon twigs $<20 \mu \mathrm{m}$ long) were essentially initiated in the prospective target layers (upper layer VI and cortical plate), although the identification of the cortical layers is not precise at these ages and on thick vibratome sections. One to 10 collaterals were counted per axon arbor, all layers confounded (mean $\pm \mathrm{SD}, 4.3 \pm 2.1$ ), with more collaterals in layer IV $(2.9 \pm 2)$ than in layers V to VI (1.4 \pm 1.1) (Table 1). At P1, the mediolateral extent of the individual TCAs in the cortical plate varied between 23 and $636 \mu \mathrm{m}$ (mean $\pm \mathrm{SD}, 244 \pm 145 \mu \mathrm{m}$ ) (see Fig. 10).

At P7, a total of 13 single TCAs was traced from deep layer VI into layer IV. Four arbors are illustrated in Figure 9. Each of the single TCAs analyzed in the present study arborized exclusively into one barrel. Some fibers ( 8 of 13 ), divided into two or three separate collateral branches in the upper layer VIa and then converged back onto the same barrel in layer IV (Fig. 9C,D). The general morphology and branching pattern of the TCAs at P7 resembles that reported previously in the adult rat (Jensen and Killackey, 1987; Arnold et al., 2001; Auso et al., 2001). However, 


\section{$\mathrm{C} 3 \mathrm{H}$}

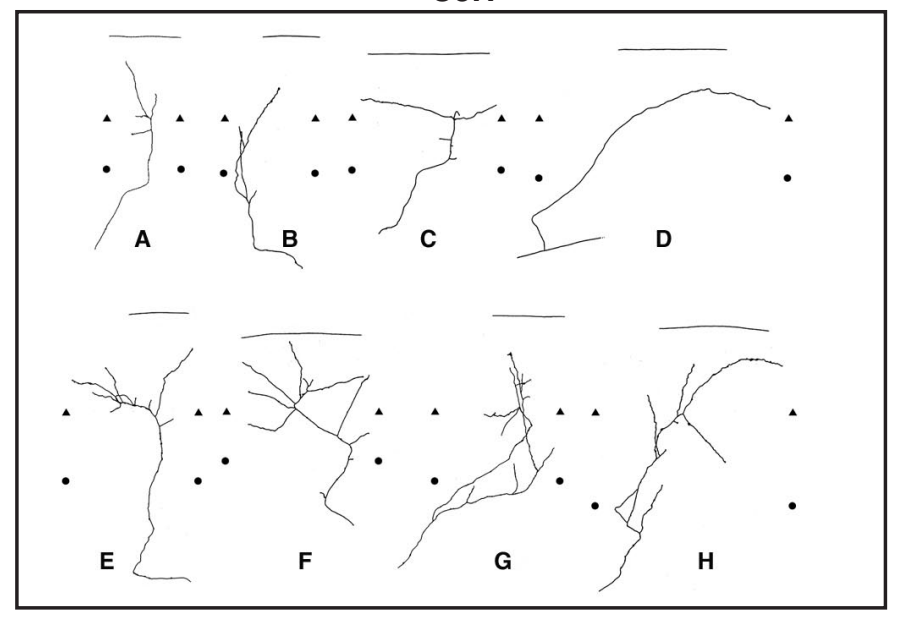

MAOA-KO

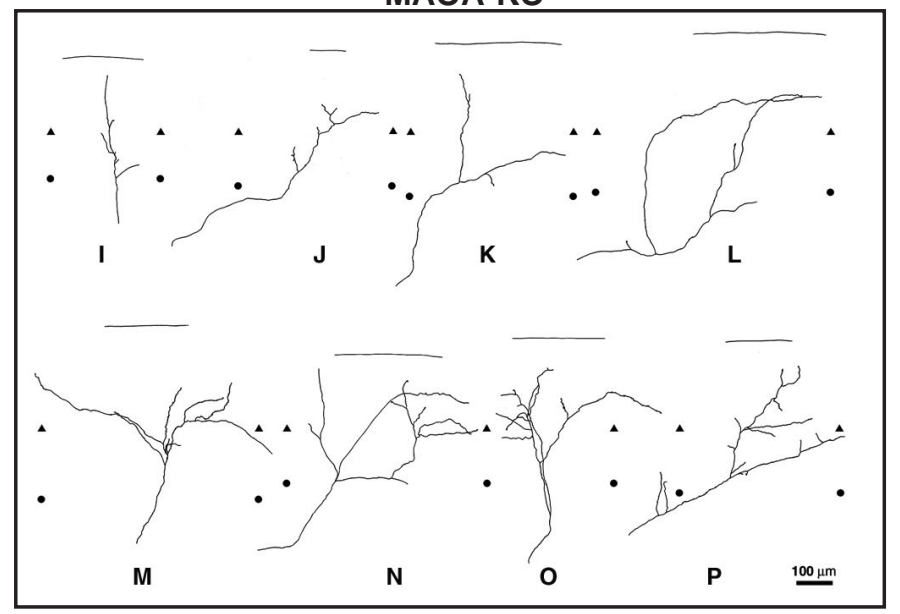

Figure 8. Single TCAs at $\mathrm{P} 1$ in the wild-type $\mathrm{C} 3 \mathrm{H}$ mice $(A-H)$ and MAOA-KO mice $(I-P)$. Individual axon arbors were selected from a total of 42 reconstructed fibers of wild-type $\mathrm{C} 3 \mathrm{H}$ mice $(A-H)$ and of 32 axons in MAOA-KO mice $(I-P)$ that were all redrawn from the posterior barrel subfield (corresponding to the large whiskers). Examples of simple axon arbors are shown in control $(A-D)$ and MAOA-KO $(I-L)$; these fibers have from one $(D)$ to four $(A, L)$ axon terminal endpoints. Examples of more complex axon arbors are shown below in control $(E-H)$ and MAOA-KO $(M-P)$ mice. These fibers have a larger number of axon branches $(6-10)$ and an irregular distribution of these branches. The heterogeneity of the axon arbors is extremely marked in both the $\mathrm{C} 3 \mathrm{H}$ and MAOA-KO mice, and no clear quantitative difference could be established between these genotypes. The upper and lower limits of layer $\mathrm{V}$ were delimited after bisbenzimide counterstaining of the sections; this delimitation comprises some uncertainties because the layers are not well defined at that age and because of the thickness of the sections. Limits between layers IV and V are indicated by triangles; limits between the layers V and VI are indicated by circles. The straight line shows the pial surface. Scale bar, $100 \mu \mathrm{m}$.

in the present sample, we observed no fibers extending over two different barrels. The tangential extent of our reconstructed fibers varied from 197 to $358 \mu \mathrm{m}$ in the plane of the slice (mean $\pm \mathrm{SD}$, $296 \pm 54 \mu \mathrm{m})$. Our estimate of the total number of cortical terminal branches ranged from 12 to 46, with a group mean \pm SD of $34 \pm 9.9$ (Table 2). These branches are essentially localized in layer IV $(32 \pm 10.9)$.

This developmental analysis of individual TC arbors shows that TCAs have already formed branches in their target layer IV by P1 and that these collaterals span variable tangential extents. Sixty percent of the TCAs extend over mediolateral distances superior to $150 \mu \mathrm{m}$, and $33 \%$ extend beyond $300 \mu \mathrm{m}$ at P1. Considering evaluations of the inter-barrel distances at P4 (estimated to be in the order of $150 \mu \mathrm{m}$ in mice from our observations) (Agmon et al., 1995), it can be estimated that more than half of the TCAs extend initially beyond one prospective barrel territory within layer IV. By P7, the number of terminal branches increases 10 -fold in layer IV, and these branches are restricted within the tangential domain of one barrel. In contrast, there is little or no increase in the number of collaterals in layer VI.

\section{Development of TC arbors in MAOA-KO mice}

Thirty-two TCAs were reconstructed from P1 TC slices in MAOA-KO mice (eight are shown in Fig. 9). As in the WT mice, the P1 TCAs had variable morphologies, some fibers appearing simple with radial directions (9 of 32) (Fig. 9I), whereas others had oblique trajectories (10 of 32) and formed branches in the lower cortical plate (Fig. 9M-P). The mean mediolateral extent of these fibers was not significantly different from that of controls ranging from 19 to $723 \mu \mathrm{m}$ (mean $\pm \mathrm{SD}, 332 \pm 220 \mu \mathrm{m}$ ) (Fig. 10). The total number of axon terminal branches in the cortex appeared to be slightly higher than in controls (Table 2); this did not reach significance when considering the total number of branches, or the number of branches in layer IV $(p=0.19)$, but was significantly increased in layer VI.

At P7, a main distinguishing feature of the TCAs in MAOA-KO mice $(n=14)$ was their heterogeneity. A few fibers resembled the TCAs of the WT mice (2 of 14), forming a terminal bouquet in layer IV (Fig. 9J), whereas all the other fibers had atypical aspects; the TCA shown in Figure 9I maintains collaterals in layer IV that are eccentric to the principal axon arbor. The fiber in Figure $9 L$ has axon branches in layer VI that are misaligned with the main arbor in layer IV; the arbor shown in Figure $9 M$ forms four collaterals in layer VI, with each having a different focus of axon arbor. This general lack of focusing of the axon arbors into one narrow tangential domain is reflected by an increase in both the mean and variance of the mediolateral spread of TCAs in MAOA-KO ranging between 277 and $654 \mu \mathrm{m}$ (mean $\pm \mathrm{SD}, 481 \pm 146)$. This is significantly different from the WT mice (ANOVA test, test $t: 0.0005$ and variance analysis). The other striking difference was a $50 \%$ reduction in the number of terminal endpoints of single axons within layer IV (Fig. 9K,L) in MAOA-KO mice compared with wild-type mice. This difference is statistically significant (Table 1) and contrasts with a normal number of terminal branches in layer VI.

Thus, the TCA arbors in layer IV of MAOA-KO mice are not significantly different from the controls at P1 but exhibit two main differences at P7: a reduced number of terminal branches in layer IV and an increased tangential extent of the TCA arbors.

\section{Development of TC arbors in the MAOA/5-HT 1B $-\mathrm{DKO}$ mice}

Single TCAs were analyzed at P7 $(n=13)$, and a sample of four of these fibers is shown (Fig. $9 E-H$ ). The general morphology of these TCAs was similar to that of the WT mice, with a general focusing of the terminal axon branches into one columnar domain. However, the tangential restriction was less stereotyped than in the WT mice; some TCAs (4 of 13) had wider collaterals in layer VI (Fig. 9E), whereas others maintained a collateral branch in layer IV out-centered from the main barrel cluster (4 of 13) $($ Fig. $9 F)$. The mediolateral extent of the TCAs was reduced 
$\mathrm{C} 3 \mathrm{H}$

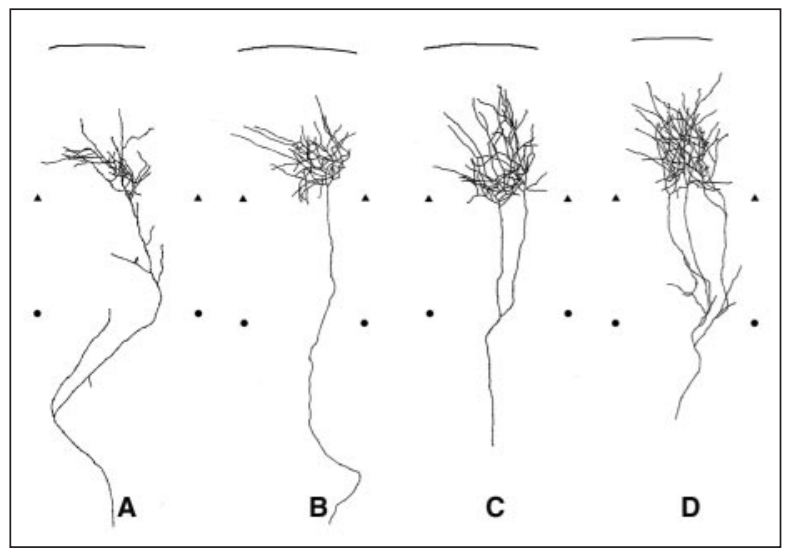

MAOA/5HT1B DKO

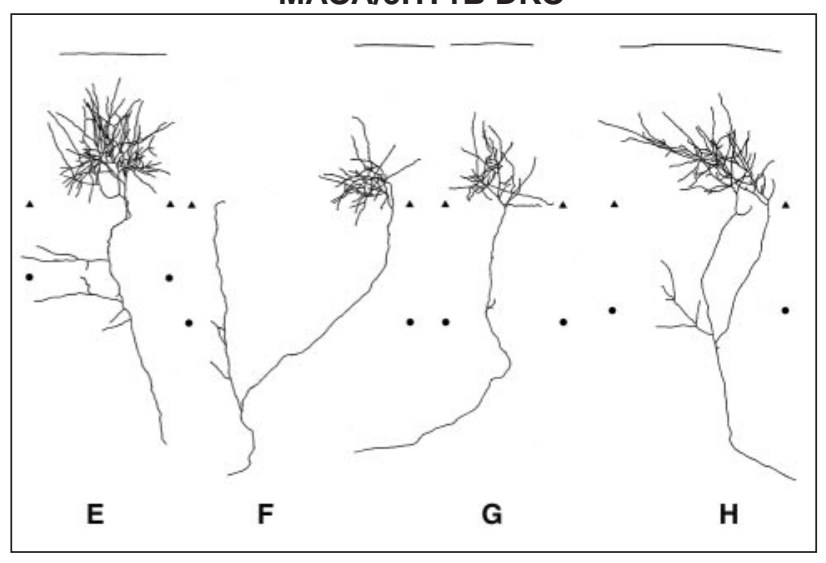

MAOA-KO

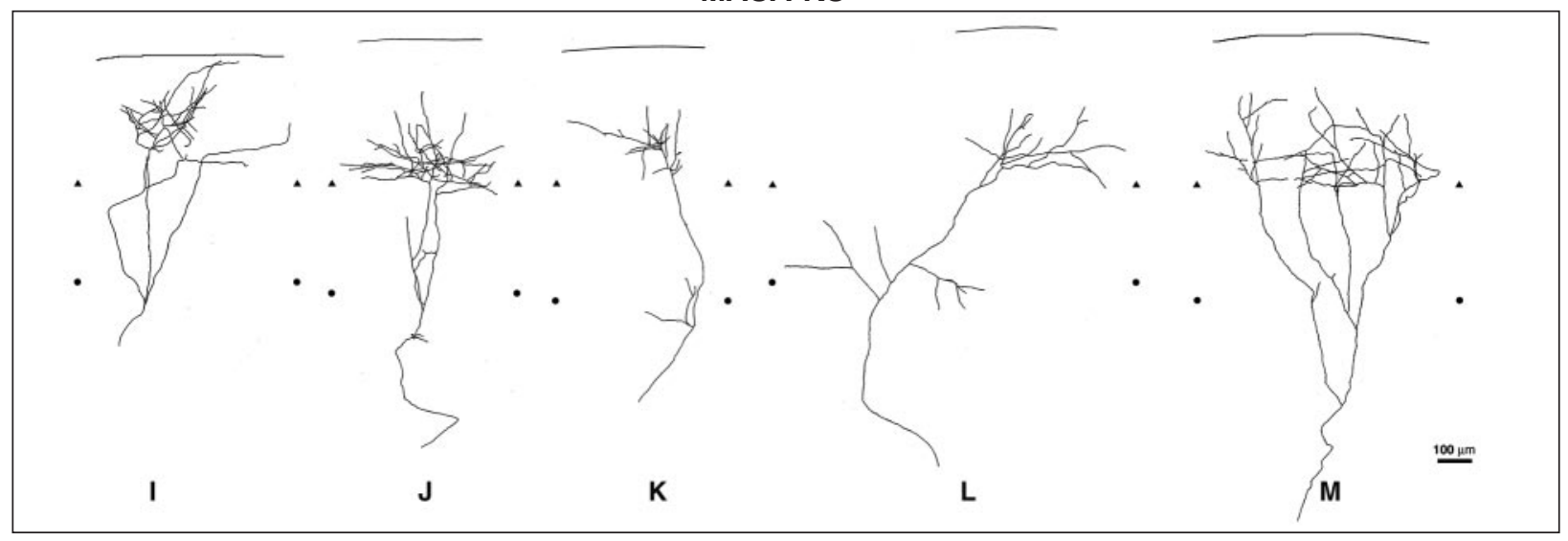

Figure 9. Single TCAs at $\mathrm{P} 7$ in wild-type $\mathrm{C} 3 \mathrm{H}(A-D)$, MAOA-KO mice $(E-I)$, and MAOA/5-HT $\mathrm{H}_{1 \mathrm{~B}}-\mathrm{DKO}$ mice. Individual axon arbors were selected from a total of 13 reconstructed fibers in $\mathrm{C} 3 \mathrm{H}$ mice, of 14 arbors in MAOA-KO mice, and of 14 in the DKO mice, which were all redrawn from the posterior barrel subfield (corresponding to the large whiskers). $A-D$, In $\mathrm{C} 3 \mathrm{H}$ mice, the axon arbor in layer IV develops from a single axon ( $B$ ) or from two $(C)$ or three $(D)$ collaterals formed in layer VI but that converge back to one domain. $A$, One axon TC arbor with a collateral branch in layer VI, which could be in the process of retracting. Within layer IV, TCAs form numerous axon collaterals, with a dominant orientation of the branches toward the barrel center, forming narrow stereotyped clusters. $E-H$, In the MAOA/5- $\mathrm{HT}_{1 \mathrm{~B}}$-DKO mice, the general morphology of the axon arbors is restored, with a prof use terminal branching. However, there are some misaligned axon branches in layers V to VI $(E)$ and in layer IV. This contributes to a more heterogeneous aspect of the fibers in the DKO mice compared with the wild-type mice. I-M, In MAOA-KO mice, the axon arbors are highly abnormal, with a reduced number of terminal branches. The orientation of the branches is disturbed. Long horizontal collaterals are visible within layer IV ( $I, L)$. Collaterals that are formed in the layer VI grow in divergent directions $(L, M)$ rather than focusing within a narrow column. Aberrant collaterals in layers $\mathrm{V}$ to VI appear to form or be maintained. The upper and lower limits of layer V were distinguished after bisbenzimide counterstaining of the sections. The limits between layers IV and V are indicated by triangles; the limit between layers V and VI are indicated by circles. The straight line shows the pial surface. Scale bar, $100 \mu \mathrm{m}$.

\section{Table 2. The number of terminal branches was estimated from TCA reconstructions at P1 and P7 in wild-type, MAOA-KO, and MAOA/5-HT B-DKO mice}

Terminal branches mean $\pm \mathrm{SD}$$$
\text { MAOA-KO }
$$

MAOA/5-HT1B DKO

P1 (total, layer I to VI)

P1 (layer I to IV)

$\mathrm{P} 1$ (layer $\mathrm{V}$ to $\mathrm{VI}$ )

P7 (total, layer I to VI)

P7 (layer I to IV)

P7 (layer V to VI)

$$
\begin{aligned}
& \text { WT }(\mathrm{C} 3 \mathrm{H}) \\
& 4.3 \pm 2.1 \quad(n=42) \\
& 2.9 \pm 2 \\
& 1.4 \pm 1.1 \\
& 34 \pm 9.9(n=13) \\
& 32 \pm 10.9 \\
& 2 \pm 3.7
\end{aligned}
$$

$$
\begin{aligned}
5 & \pm 2.6(n=32) \\
2.8 & \pm 2.1 \\
2.2 & \pm 1.6 \\
19.8 & \pm 8.1(n=14) \\
16.3 & \pm 8.4
\end{aligned}
$$$$
3.5 \pm 3.2
$$

compared with MAOA-KO mice but remained wider than in controls (mean $\pm \mathrm{SD}, 389 \pm 140 \mu \mathrm{m}$ ). The overall number of terminal branches that were formed in the cortex appeared to be normalized. However, a differential effect is observed in the cortical layers; in layer VI, there was an increased number of collaterals compared with wild-type mice (Table 2). Thus, the barrel rescue in the $\mathrm{MAOA} / 5-\mathrm{HT}_{1 \mathrm{~B}}-\mathrm{DKO}$ is associated with a normal branching and an axon growth oriented toward barrel domain in layer IV, but some mislocalized collaterals are maintained, particularly those formed in layer VI, resulting in an increased tangential extent. These observations at the single axon level are consistent with our observations with 5-HTT immuno- 


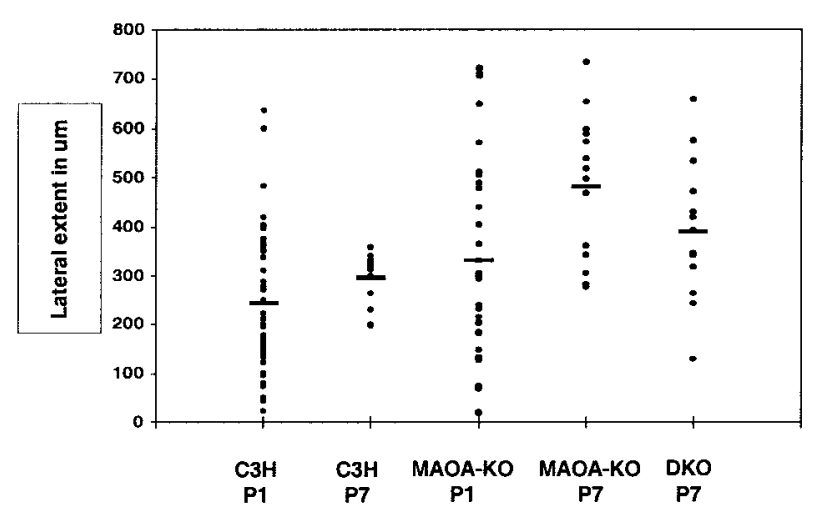

Figure 10. Histogram of the tangential extent of the TCAs in layer IV. The maximal mediolateral extent of the TCAs was measured within layer IV by plotting the endpoints of the arbor on a plane parallel to the pial surface. The individual values of each arbor were plotted and aligned for each age ( $\mathrm{P} 1$ and $\mathrm{P} 7)$ and for each genotype: wild type $(\mathrm{C} 3 \mathrm{H})$, MAOA$\mathrm{KO}$, and MAOA-5-HT ${ }_{1 \mathrm{~B}}$-DKO. The mean value is indicated by a bar. In P1 control mice, the tangential widths of the TCAs are heterogeneous $(23-636 \mu \mathrm{m})$ as reflected by the wide scatter of the individual values above and below the mean. In control P7 mice, this variability decreases (from 197 to 358), and the tangential extent of each fiber is close to the mean value. In the P1 MAOA-KO mice, the tangential extent of the TCAs is not significantly different from that observed in $\mathrm{C} 3 \mathrm{H}$ mice and is widely scattered; in P7 MAOA-KO mice, the heterogeneity of the TCA distribution is maintained, together with a general increase in the mediolateral extent of the fibers. In the P7 MAOA $/ 5-\mathrm{HT}_{1 \mathrm{~B}}-\mathrm{DKO}$ mice, there is a more heterogeneous distribution of the fibers than in control mice, and the mean value lies between the values of the control and MAOA-KO mice.

staining in the DKO at P7, showing that axon clusters form in layer IV but not in layer VI.

\section{DISCUSSION}

The present study sheds new light on the emergence of thalamic axon patterning in the primary somatosensory cortex. We show that the somatosensory TCAs have initially a broad and continuous distribution in their target cell layer IV during a period of $2 \mathrm{~d}$ before coalescing into barrel domains. Second, we find that the barrel-deficient phenotype of MAOA-KO mice is linked to a reduced branching in layer $\mathrm{IV}$, a misoriented growth of the TC axon collaterals, and possibly a lack of retraction of axon branches. Finally, we provide evidence that $5-\mathrm{HT}_{1 \mathrm{~B}}$ receptors control the tangential spread and the number of terminal branches of TCAs in MAOA-KO mice.

\section{Periphery-related patterns emerge from a uniform distribution of TCAs in layer IV}

The general topography of the thalamocortical projections is established during early embryonic development, independently of inputs from the periphery (Dawson and Killackey, 1985; Molnar et al., 1995), and is most likely dependent on gene expression gradients and chemotactic cues in cortical target areas and thalamic neurons (Bishop et al., 2000; Vanderhaeghen et al., 2000; Fukuchi-Shimogori and Grove, 2001). However, the way TCAs, belonging to a functionally related group of receptors, assemble into one cortical column is not understood.

Based on the labeling of specific thalamic sensory afferents with 5-HTT, we find that the TCAs already contact their target neurons in layer IV on the day of birth, confirming previous observations (Senft and Woolsey, 1991). We found no evidence for a prepatterning of the TC projection in the deep cortical layers; periphery-related patterns of the TC axons appeared only after the TCAs had reached layer IV, and axon clusters were always more clearly defined in layer IV than in layer VI, suggesting that the primary event of axon patterning could occur in layer IV or be initiated simultaneously in layers IV and VI. Thus, our observations do not support previous suggestions that the peripheryrelated patterning initially emerges in the deep cortical layers or subplate (Agmon et al., 1993; Schlaggar and O'Leary, 1994).

The uniform distribution of the TCAs within layer IV and the observation of a tangential plexus of fibers in this layer suggested that the TCAs have initially some degree of overlap and only subsequently become separated into disjunctive columns. The appearance of septa delineating the thalamic clusters indicates that some TCAs are cleared away of this cortical space, suggesting that these fibers are either retracted or displaced. How can these events be correlated with a reshaping of the individual TC arbors? Our analysis of a wide population of single TC axon arbors indicates that, before periphery-related patterns appear, at $\mathrm{P} 1$, the tangential extent of the $\mathrm{TC}$ terminal arbors is variable, with $60 \%$ of the TC arbors covering distances superior to one prospective barrel. This suggests that the formation of axon clusters, by $\mathrm{P} 3$, involves some retraction of axon collaterals, besides the addition of axon branches. It will, however, be necessary to analyze single axon arbors at the time when barrels emerge to determine more accurately how the reshaping of the individual TC arbors can be related with the emergence of the peripheryrelated patterns.

Our observations are in agreement with previous observations by Senft and Woolsey (1991) who noted that individual TC fibers span regions wider than one individual barrel to create a uniform tangential distribution of the TCAs in layer IV at early ages. In contrast, other developmental analyses saw no evidence for the formation of exuberant TCA branches in layers IV (Agmon et al., 1993) but showed no examples of single axon arbors before barrel formation. The difference noted with the extensive single fiber analysis performed in rats (Catalano et al., 1996) is more difficult to explain but may be related to the earlier tempo of maturation in rats in which the barrel rows are already delimited on the day of birth (Schlaggar and O'Leary, 1994). In fact, the present interpretation is also coherent with the retrograde tracing analyses of Agmon et al. (1995), indicating that the somatosensory TCA projections are less precise at P0 than at P4. Similar refinement of axon overgrowth is visible in many other sensory maps, such as the visual system (Antonini and Stryker, 1993; Katz and Shatz, 1996) or the olfactory system (Potter et al., 2001), and could be related to the dynamic behavior of the ingrowing axons as they reach out for their target neurons (Cohen-Cory, 1999). Our observations suggest that a similar scenario of focused branch stabilization and collateral back branching occurs during the normal formation of barrels.

Interestingly, a preclustering period was noted for TCAs within layer IV in the somatosensory cortex of wallabies. In this species, the development of the somatosensory system is protracted during postnatal life, and it has been possible to identify a rather long developmental stage during which the TCAs have reached their target cells but do not yet form clusters (Marotte et al., 1997). These results suggest that maturation of layer IV provides an essential permissive signal to the TCAs. On the other hand, several studies on different species have indicated that the organization of patterns depends on the intrinsic properties of the thalamic neurons and/or on signals that are transmitted from the periphery. Thalamic clusters can form in an abnormal cortical 
environment, such as in a heterotopic cortical graft (Schlaggar and O'Leary, 1991), or in mutants with a disorganized cortical structure, such as the reeler mouse (Molnar et al., 1998).

\section{Altered thalamocortical branching in MAOA-KO mice}

In MAOA-KO mice, normal periphery-related patterns are restored by reducing the brain levels of 5-HT during the first postnatal week (Cases et al., 1996), suggesting that the initial stages of thalamocortical development during embryonic life are not altered. In the present study, we found that the time course of the TCA laminar ingrowth and refinement was identical in MAOA-KO and control mice. Furthermore, analysis of single axon arbors did not reveal significant exuberant tangential overgrowth of the TCAs at early developmental stages (P1).

The formation of axon collaterals in target layers appears to be an important factor in the elaboration of axon cluster patterns. There was a 10-fold increase in the number of collateral axon branches in layer IV between P1 and P7 in agreement with previous qualitative descriptions in rats (Catalano et al., 1996) and mice (Agmon et al., 1993). In MAOA-KO mice, this collateral branching was altered, with a significant $50 \%$ reduction in the number of terminal branches. The latter deficit is, however, not sufficient to explain the barrel-deficient phenotype, because normal periphery-related patterns can emerge in situations in which a severe reduction in TC terminal axon branches is observed, for instance, in hypothyroid rats (Auso et al., 2001). A second abnormality of the TCAs in MAOA-KO mice was the loss of the oriented growth of the TCA branches within layer IV; in normal mice, a majority of TC branches is directed toward the center of one barrel, whereas this directionality is lost in MAOA-KO mice. Furthermore, a lack of retraction of misplaced axon collaterals could occur in MAOA-KO mice. At P7, the tangential spread of the TC arbors remained variable and was $40 \%$ larger than in controls. This suggests that, although abnormally localized axon branches retract and reorient their trajectories in normal mice, they do not retract and continue growing in MAOA-KO mice.

\section{Role of the $5-\mathrm{HT}_{1 \mathrm{~B}}$ receptor in the alterations of TC arborization}

We find that the time course of TCA patterning in the S1 of the MAOA/5-HT $\mathrm{H}_{1 \mathrm{~B}}-\mathrm{DKO}$ mice was restored to normal, confirming a key role of the 5- $\mathrm{HT}_{1 \mathrm{~B}}$ receptor in the developmental abnormalities of MAOA-KO mice (Salichon et al., 2001). This effect could be mediated by changes in neural activity in the thalamocortical circuits. In the TC slice preparation, $5-\mathrm{HT}_{1 \mathrm{~B}}$ receptor stimulation decreased TC responses to low-frequency stimulation and relieved the short-term depression induced by high-frequency TC stimulation (Laurent et al., 2002). In this scheme, 5-HT ${ }_{1 \mathrm{~B}}$ receptors could enhance correlated activity patterns of TC afferents that are related to one functional domain, resulting in the stabilization of neighboring coactive TCAs (Isaac et al., 1997; Feldman et al., 1999). Thus, overactivation of the $5-\mathrm{HT}_{1 \mathrm{~B}}$ receptors could alter activity-dependent stabilization of TCA branches. Alternatively, overactivation of the $5-\mathrm{HT}_{1 \mathrm{~B}}$ receptors could alter the response of thalamic axons to chemotropic or repulsive cues. The $5-\mathrm{HT}_{1 \mathrm{~B}}$ receptor is negatively coupled to adenylate cyclase (AC), and AC1 KO mice have a barrelless phenotype that resembles that of MAOA-KO mice (Welker et al., 1996). Because levels of cAMP modify the behavior of axons to chemotropic cues (Song and Poo, 1999), it is possible that reduced cAMP via excessive $5-\mathrm{HT}_{1 \mathrm{~B}}$ receptor stimulation in the thalamic afferents could reduce their sensitivity to growth-promoting or repulsive molecules implicated in the formation of barrels.

\section{REFERENCES}

Agmon A, Connors BW (1991) Thalamocortical responses of mouse somatosensory (barrel) cortex in vitro. Neuroscience 41:365-379.

Agmon A, Yang LT, O'Dowd DK, Jones EG (1993) Organized growth of thalamocortical axons from the deep tier of terminations into layer IV of developing mouse barrel cortex. J Neurosci 13:5365-5382.

Agmon A, Yang LT, Jones EG, O’Dowd DK (1995) Topological precision in the thalamic projection to neonatal mouse barrel cortex. J Neurosci 15:549-561.

Antonini A, Stryker MP (1993) Development of individual geniculocortical arbors in cat striate cortex and effects of binocular impulse blockade. J Neurosci 13:3549-3573.

Arnold PB, Li CX, Waters RS (2001) Thalamocortical arbors extend beyond single cortical barrels: an in vivo intracellular tracing study in rat. Exp Brain Res 136:152-168.

Auso E, Cases O, Fouquet C, Camacho M, Garcia-Velasco JV, Gaspar P, Berbel P (2001) Protracted expression of serotonin transporter and altered thalamocortical projections in the barrelfield of hypothyroid rats. Eur J Neurosci 14:1968-1980.

Bishop KM, Goudreau G, O'Leary DD (2000) Regulation of area identity in the mammalian neocortex by $\mathrm{Emx} 2$ and Pax6. Science 288:344-349.

Cases O, Seif I, Grimsby J, Gaspar P, Chen K, Pournin S, Muller U, Aguet M, Babinet C, Shih JC (1995) Aggressive behavior and altered amounts of brain serotonin and norepinephrine in mice lacking MAOA. Science 268:1763-1766.

Cases O, Vitalis T, Seif I, De Maeyer E, Sotelo C, Gaspar P (1996) Lack of barrels in the somatosensory cortex of monoamine oxidase A-deficient mice: role of a serotonin excess during the critical period. Neuron 16:297-307.

Cases O, Lebrand C, Giros B, Vitalis T, De Maeyer E, Caron MG, Price DJ, Gaspar P, Seif I (1998) Plasma membrane transporters of serotonin, dopamine, and norepinephrine mediate serotonin accumulation in atypical locations in the developing brain of monoamine oxidase $\mathrm{A}$ knock-outs. J Neurosci 18:6914-6927.

Catalano SM, Robertson RT, Killackey HP (1996) Individual axon morphology and thalamocortical topography in developing rat somatosensory cortex. J Comp Neurol 367:36-53.

Cohen-Cory S (1999) BDNF modulates, but does not mediate, activitydependent branching and remodeling of optic axon arbors in vivo. J Neurosci 19:9996-10003.

Dawson DR, Killackey HP (1985) Distinguishing topography and somatotopy in the thalamocortical projections of the developing rat. Brain Res 349:309-313.

Erzurumlu RS, Jhaveri S (1990) Thalamic axons confer a blueprint of the sensory periphery onto the developing rat somatosensory cortex. Dev Brain Res 56:229-234.

Fairen A, Cobas A, Fonseca M (1986) Times of generation of glutamic acid decarboxylase immunoreactive neurons in mouse somatosensory cortex. J Comp Neurol 251:67-83.

Feldman DE, Nicoll RA, Malenka RC (1999) Synaptic plasticity at thalamocortical synapses in developing rat somatosensory cortex: LTP, LTD, and silent synapses. J Neurobiol 41:92-101.

Fukuchi-Shimogori T, Grove EA (2001) Neocortex patterning by the secreted signaling molecule FGF8. Science 294:1071-1074.

Hannan AJ, Blakemore C, Katsnelson A, Vitalis T, Huber KM, Bear M, Roder J, Kim D, Shin HS, Kind PC (2001) PLC-beta1, activated via mGluRs, mediates activity-dependent differentiation in cerebral cortex. Nat Neurosci 4:282-288.

Hansson SR, Mezey E, Hoffman BJ (1998) Serotonin transporter messenger RNA in the developing rat brain: early expression in serotonergic neurons and transient expression in non-serotonergic neurons. Neuroscience 83:1185-1201.

Isaac JT, Crair MC, Nicoll RA, Malenka RC (1997) Silent synapses during development of thalamocortical inputs. Neuron 18:269-280.

Iwasato T, Erzurumlu RS, Huerta PT, Chen DF, Sasaoka T, Ulupinar E, Tonegawa S (1997) NMDA receptor-dependent refinement of somatotopic maps. Neuron 19:1201-1210.

Iwasato T, Datwani A, Wolf AM, Nishiyama H, Taguchi Y, Tonegawa S, Knopfel T, Erzurumlu RS, Itohara S (2000) Cortex-restricted disruption of NMDAR1 impairs neuronal patterns in the barrel cortex. Nature 406:726-731.

Jensen KF, Killackey HP (1987) Terminal arbors of axons projecting to the somatosensory cortex of the adult rat. I. The normal morphology of specific thalamocortical afferents. J Neurosci 7:3529-3543.

Jhaveri S, Erzurumlu RS, Crossin K (1991) Barrel construction in rodent neocortex: role of thalamic afferents versus extracellular matrix molecules. Proc Natl Acad Sci USA 88:4489-4493.

Katz LC, Shatz CJ (1996) Synaptic activity and the construction of cortical circuits. Science 274:1133-1138.

Laurent A, Goaillard JM, Cases O, Lebrand C, Gaspar P, Ropert N (2002) Activity dependent presynaptic role of the serotonin 1B receptors on the thalamocortical transmission in the somatosensory pathway of the neonatal mice. J Neurosci 22:886-900. 
Lebrand C, Cases O, Adelbrecht C, Doye A, Alvarez C, El Mestikawy S, Seif I, Gaspar P (1996) Transient uptake and storage of serotonin in developing thalamic neurons. Neuron 17:823-835.

Lebrand C, Cases O, Wehrle R, Blakely RD, Edwards RH, Gaspar P (1998) Transient developmental expression of monoamine transporters in the rodent forebrain. J Comp Neurol 401:506-524.

Lieske V, Bennett-Clarke CA, Rhoades RW (1999) Effects of serotonin on neurite outgrowth from thalamic neurons in vitro. Neuroscience 90:967-974.

Lotto B, Upton L, Price DJ, Gaspar P (1999) Serotonin receptor activation enhances neurite outgrowth of thalamic neurons in rodents. Neurosci Lett 269:87-90.

Maier DL, Mani S, Donovan SL, Soppet D, Tessarollo L, McCasland JS, Meiri KF (1999) Disrupted cortical map and absence of cortical barrels in growth-associated protein (GAP)-43 knockout mice. Proc Natl Acad Sci USA 96:9397-9402.

Marotte LR, Leamey CA, Waite PM (1997) Timecourse of development of the wallaby trigeminal pathway. III. Thalamocortical and corticothalamic projections. J Comp Neurol 387:194-214.

Molnar Z, Blakemore C (1995) How do thalamic axons find their way to the cortex. Trends Neurosci 18:389-396.

Molnar Z, Adams R, Goffinet AM, Blakemore C (1998) The role of the first postmitotic cortical cells in the development of thalamocortical innervation in the reeler mouse. J Neurosci 18:5746-5765.

Potter SM, Zheng C, Koos DS, Feinstein P, Fraser SE, Mombaerts P (2001) Structure and emergence of specific olfactory glomeruli in the mouse. J Neurosci 21:9713-9723.

Rhoades RW, Bennett-Clarke CA, Chiaia NL, White FA, McDonald GJ, Haring JH, Jacquin MF (1990) Development and lesion induced reorganization of the cortical representation of the rat's body surface as revealed by immunohistochemistry for serotonin. J Comp Neurol 293:190-207.

Rhoades RW, Bennett-Clarke CA, Shi MY, Mooney RD (1994) Effects of 5-HT on thalamocortical synaptic transmission in the developing rat. J Neurophysiol 72:2438-2450.

Rice FL, Van der Loos H (1977) Development of the barrels and barrel field in the somatosensory cortex of the mouse. J Comp Neurol 171:545-560

Salichon N, Gaspar P, Upton AL, Picaud S, Hanoun N, Hamon M, De Maeyer E, Murphy DL, Mossner R, Lesch KP, Hen R, Seif I (2001) Excessive activation of serotonin (5-HT) 1B receptors disrupts the formation of sensory maps in monoamine oxidase A and 5-HT transporter knock-out mice. J Neurosci 21:884-896.

Schlaggar BL, O'Leary DD (1991) Potential of visual cortex to develop an array of functional units unique to somatosensory cortex. Science 252:1556-1560.

Schlaggar BL, O'Leary DD (1994) Early development of the somatotopic map and barrel patterning in rat somatosensory cortex. J Comp Neurol 346:80-96.

Senft SL, Woolsey TA (1991) Growth of thalamic afferents into mouse barrel cortex. Cereb Cortex 1:308-335.

Song HJ, Poo MM (1999) Signal transduction underlying growth cone guidance by diffusible factors. Curr Opin Neurobiol 9:355-363.

Vanderhaeghen P, Lu O, Prakash N, Frisen J, Walsh CA, Frostig RD, Flanagan JG (2000) A mapping label required for normal scale of body representation in the cortex. Nat Neurosci 3:358-365.

Van der Loos H, Woolsey TA (1973) Somatosensory cortex: structural alterations following early injury to sense organs. Science 179:395-398.

Vitalis T, Cases O, Callebert J, Launay JM, Price DJ, Seif I, Gaspar P (1998) Effects of monoamine oxidase A inhibition on barrel formation in the mouse somatosensory cortex: determination of a sensitive developmental period. J Comp Neurol 393:169-184.

Welker C (1971) Microelectrode delineation of fine grain somatotopic organization of (SMI) cerebral neocortex in albino rat. Brain Res 26:259-275.

Welker E, Armstrong-James M, Bronchti G, Ourednik W, GheorghitaBaechler F, Dubois R, Guernsey DL, Van der Loos H, Neumann PE (1996) Altered sensory processing in the somatosensory cortex of the mouse mutant barrelless. Science 271:1864-1867.

Woolsey TA, Van der Loos H (1970) The structural organization of layer IV in the somatosensory region (SI) of mouse cerebral cortex. The description of a cortical field composed of discrete cytoarchitectonic units. Brain Res 17:205-242. 